\title{
Identifying Phenomena and Developing Sustainable Engineering Educational Modules that Integrate STEM Education Best Practices and Next Generation Science Standards for Middle School Science Teachers
}

\section{Mr. Michael Lorenzo Greene, Arizona State University, Polytechnic campus}

Michael Greene is a PhD Student at Arizona State University. He is pursuing his degree in the Engineering Education Systems and Design program, concurrently while pursuing a Master's degree in Engineering. Michael graduated with his B.S. in Mechanical engineering from University of Pittsburgh in April of 2018. His research interest lies in diversity, inclusion and K-12 engineering pedagogy.

\section{Ms. Christine Nguyen, University of Pittsburgh}

Christine Nguyen is a full stack software engineer at the Global Biosocial Complexity Initiative at Arizona State University who builds and maintains computational social science open source software to (1) investigate factors influencing human behavior and collective action in socioecological systems, (2) support integrative research and data analysis on long-term socio-ecological dynamics, and (3) preserve the digital context necessary to ensure reproducible scientific computation. She obtained her bachelor's degree in Computer Engineering from the University of Pittsburgh in December 2018.

\section{Dr. David V.P. Sanchez, University of Pittsburgh}

David Sanchez is an Assistant Professor in the Department of Civil \& Environmental Engineering and the Assistant Director for the Mascaro Center for Sustainable Innovation. His research is focused on fusing sustainability principles and design thinking to address the Water and Energy grand challenges in the natural and built environment. Current projects include: Renewable electrode materials for Bioelectrochemical systems, Recirculating Aquaponic Systems, Environmental Quality wireless sensor networks, and incorporating Sustainable Design/Innovation into engineering curricula. He serves as a director for Pitt's Design EXPO, the Manufacturing Assistance Center's makerspace and, a variety of the Mascaro Center's Sustainability Outreach and Education programs including the Manchester Academic Charter School "Green week" and the Teach the Teacher program, impacting thousands of students each year. Dr. Sanchez teaches Introduction to Sustainable Water Technology and Design, classes in the Civil \& Environmental Engineering Department and the Swanson School of Engineering First-Year program. He works directly with K-12 initiatives and outreach programs including Constellation Energy Inventor Labs. 


\section{Identifying Phenomena and Developing Educational Modules that Integrate Engineering, Sustainability and Next Generation Science Standards for Middle School Science Teachers (Resource Exchange)}

Contact: Dr. David Sanchez (davidsanchez@pitt.edu), Michael Greene (mlgree16@asu.edu), Christine Nguyễn (christine.n.nguyen@asu.edu)

\section{Overview and Objectives}

During summer 2018, three educational modules were designed to expand on middle school curriculum by integrating concepts of engineering and sustainability while adhering to Next Generation Science Standards (NGSS). These modules were initially presented at a two-day professional development workshop "Teach the Teacher," where a group of southwestern Pennsylvania middle school teachers engaged the modules as students. The goals for this workshop were to teach participating teachers how to solve problems like an engineer via the engineering design process, demonstrate how teachers can incorporate NGSS standards into their curriculum, and exhibit the educational value of engineering design and sustainability principles through the modules.

\section{Module Design}

To build the modules, a design process was created that engaged various STEM teaching practices: the four key principles of learning, three principles of project-based learning, guided design approach and active learning.

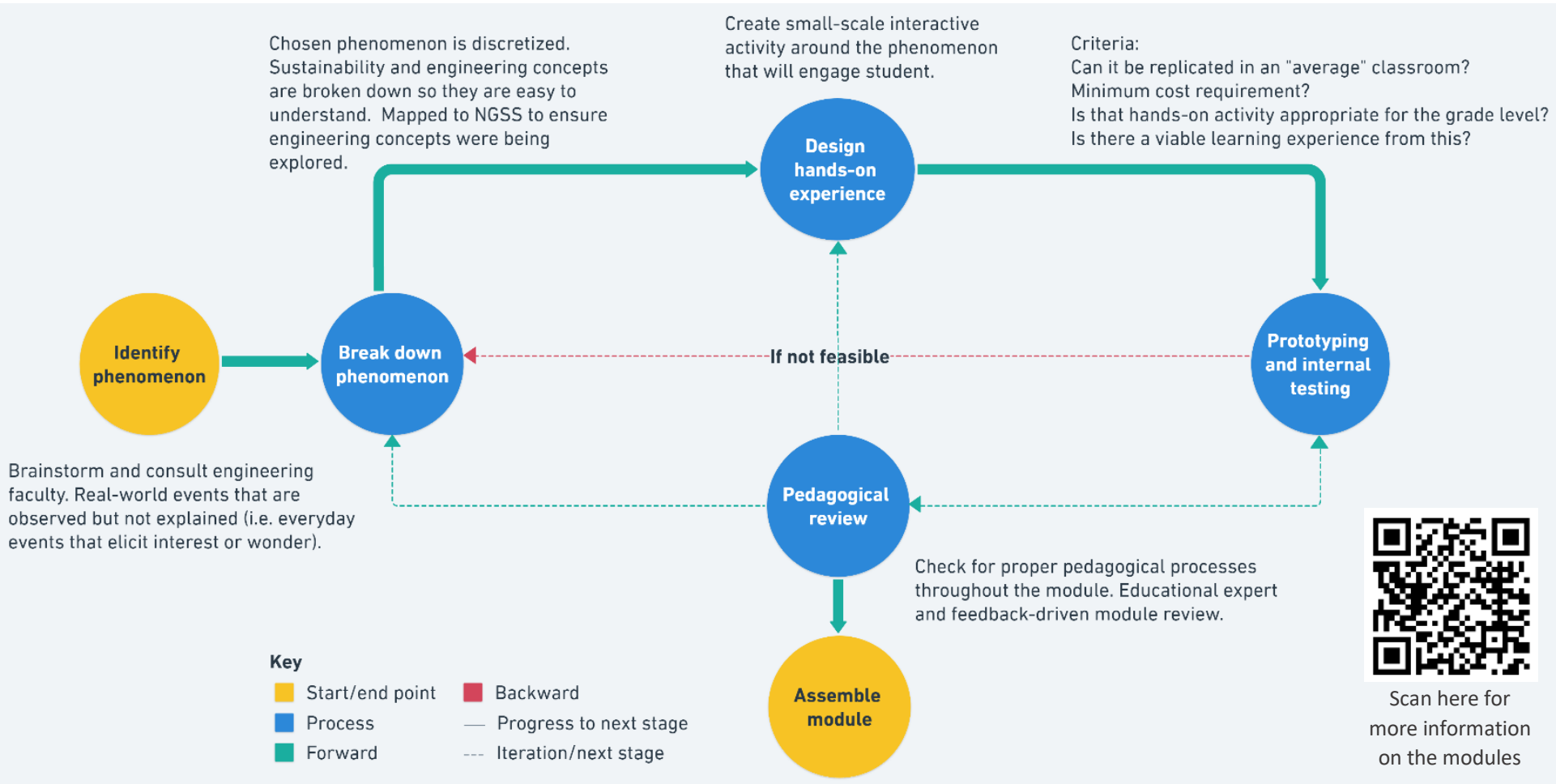

Figure 1: Design Process Followed to Develop the Three Educational Modules Presented at the "Teach the Teacher" Workshop

Choosing Phenomena. In the first step of developing the modules, the phenomenon is introduced to illicit preexisting knowledge, experience and mental models of misconceptions. Various routes were taken to identify the phenomenon: brainstorming, pinpointing contradictions or conferring with engineering university faculty or professionals. Next, the phenomenon is broken down so that it can be easily understood and mentally organized by students and framed in the context of hands-on engineering design challenges in the modules. During this process, the phenomenon is also mapped to NGSS to ensure that material would be appropriate for a middle school teaching environment.

Hands-On Activities. Each module included hands-on engineering design challenges for the students to perform while working through the associated phenomenon. During these activities, students are required to work in pairs, which facilitates an environment conducive to learning through collaboration and integrative complexity. Additionally, after each section of the modules, students are required to reflect on their own reasoning, which challenges them to compare their misconceptions about a concept before the module and their 
findings after the module. Incorporating active learning and backwards design help to establish engineering fundamentals through problem solving in real-world contexts, which fosters superior understanding and relatability.

Pedagogical Review. The modules were evaluated based on the following criteria: overall learning experience, correlation with NGSS, accessibility for middle school teachers, costs and ease of reproducing the modules in class. During the pedagogical review process, the professor and engineering students collaboratively reviewed the modules to evaluate presentation, hands-on activities, organization of content, and student-instructor interactions.

Professor Interviews. Interviews with engineering professors were incorporated into the modules to frame problems with meaningful context and deepen students' understanding of the phenomenon.

\section{"Teach the Teacher" Workshop}

\begin{tabular}{l|llll} 
Module & Engineering Concept & Phenomenon & Story & NGSS \\
\hline $\begin{array}{l}\text { Reclaiming } \\
\text { Waste }\end{array}$ & $\begin{array}{l}\text { Physical and chemical } \\
\text { separations }\end{array}$ & Water treatment & $\begin{array}{l}\text { Cleaning the Great Pacific } \\
\text { Garbage Patch }\end{array}$ & $\begin{array}{l}\text { MS-ETS1-1, MS-ETS1- } \\
\text { 2, MS-ETS1-3 }\end{array}$ \\
$\begin{array}{l}\text { Power of } \\
\text { Music }\end{array}$ & $\begin{array}{l}\text { Transformation of } \\
\text { energy }\end{array}$ & $\begin{array}{l}\text { Hearing, } \\
\text { eardrums, speakers }\end{array}$ & $\begin{array}{l}\text { technology; human } \\
\text { eardrum; creating beats with } \\
\text { Dr. Dre }\end{array}$ & MS-PS4-1, MS-PS4-2 \\
& & & & Psing everyday objects that \\
Charged $U p$ & Energy storage & $\begin{array}{l}\text { Storing } \\
\text { energy/batteries }\end{array}$ & $\begin{array}{l}\text { PS2-3, PS2-5, PS1-1, } \\
\text { store energy for later use }\end{array}$ & $\begin{array}{l}\text { MS-PS3-3, 3-5-ETS-1, 3- } \\
\text { 5-ETS-1-2, 3-5-ETS-1-3 }\end{array}$
\end{tabular}

Figure 2: Three Educational Modules Piloted at "Teach the Teacher"

Reclaiming Waste. The Great Pacific Garbage Patch is used as a narrative to introduce the water treatment phenomenon and illustrate the problem in a relatable real-world context. During this module, students are work in teams on a hands-on engineering challenge to clean a mystery solution by separating various components like a water treatment plant. Separation includes removing metals, plastics, liquids and aggregates from the solution. As students perform the separation, they are required to collect and record data in trials while following procedures, brainstorm and design a better separation methodology, and reflect on their results.

Power of Music. Various experiments were conducted to elicit the phenomenon of energy transformation. In this module, students worked in pairs to create their own string phone to observe how sound travels; model eardrum to visually and kinesthetically conceptualize transforming sound into energy; and speaker to explore the transformation of electrical energy into sound. Throughout the module, students collect and record their observations, make educated guesses about how sound travels and the factors that may affect the ability of sound to travel, and draw diagrams to represent energy transformation and sound travel.

Charged Up. The phenomenon of energy storage is introduced in the context of the dependence on electricity to power modern technologies such as smartphones, electrical cars and batteries. Students explore energy storage by designing and prototyping various capacitors with aluminum foil, printer paper and masking tape. After creating the capacitors, they are charged with a 9-V battery and measured with a multimeter. Students collect data, make observations and use the information they learned to make recommendations to improve capacitor designs for larger energy storage.

Post-Workshop Evaluation. All participating middle school teachers completed post-workshop surveys with rating scale and open response questions. After the workshop, teachers felt more confident in incorporating and building modules around engineering and sustainability. In particular, teachers were motivated to integrate process analysis, problem identification, and solution development and design activities. 